\title{
Nature Clinical Practice on the Internet: adding value online
}

\author{
Heather B Wood and Helen E King
}

The Web is increasingly the first port of call for clinicians and scientists who want to keep abreast of the current literature. Like many other medical publishers, Nature Clinical Practice is responding to the demand for clinical web resources by providing a range of online features and services that facilitate access and add value to the journal content. So, what can Nature Clinical Practice Nephrology offer to our readers online?

Each month, the journal homepage (http:// www.nature.com/ncpneph) highlights two new articles that are available to view free of charge, thereby enabling non-subscribers to the journal to sample its content. Subscribers can access full journal content online, and can download full-text articles from the latest issue to read on a mobile device such as a PDA or cell phone (see http:// www.nature.com/ncpneph/about_journal/pda services.html). To ensure that they never miss a crucial article, readers can register to receive tables of content by e-mail-click on 'Sign up for e-alerts' on the homepage for more information. Tables of content are also available through an RSS news feed; details can be found at http://www.nature.com/ncpneph/about_journal/ newsfeeds.html.

To help maximize the timeliness of the journal content, we now provide Viewpoints and Practice Points online ahead of print, and we plan to extend advance online publication to the other article types in the coming months. The articles currently available ahead of print can be found at http://www.nature.com/ ncpneph/journal/vaop/ncurrent.

The online version of Nature Clinical Practice Nephrology provides supplementary material that cannot be accommodated in print, such as large figures or tables. Movies are another valuable online feature.

Another online-only feature is the Article Response, which gives readers an opportunity

...Nature
Publishing
Group is
developing
new web
initiatives to
keep clinicians
informed
about recent
developments
in their field...

to comment on specific articles featured within the journal. Further information on submitting Article Responses, as well as other article types, can be found in our instructions for authors at http://www.nature.com/ncpneph/ about_journal/author_information.html.

In addition to the features of the Nature Clinical Practice websites, Nature Publishing Group is developing new web initiatives to keep clinicians informed about recent developments in their field and to enable them to share this information with their colleagues. Dissect Medicine (http://www.dissectmedicine.com) is a collaborative medical news website, which indexes and ranks international medical news. Dissect Medicine users submit news items for review, along with tags and keywords. The news items are then ranked by the user group to ensure that only the most relevant and influential articles make it as current headline stories. You can gain a quick overview of the latest medical news without registering to the service. To fully participate by posting links to stories or by voting you need to become a registered user, but registration is free and takes only a few seconds.

Connotea $^{\circledR}$ (http://www.connotea.org; HM Publishers Holdings Limited, Basingstoke, UK) is a free online reference manager and 'social bookmarking' tool that provides a place to store links to the articles you read and the websites you use. Most Nature Clinical Practice articles appear in Connotea ${ }^{\circledR}$ and are tagged using the authors' keywords. You can discover new articles and websites by sharing your links with other users, and your links and saved references are instantly accessible from any computer.

We will keep our readers informed of future web developments relating to the journal, and we welcome suggestions as to how we might enhance your online experience of Nature Clinical Practice Nephrology. 